\title{
Splenosis. A Diagnosis to be Considered
}

\author{
Jorge C. Ribeiro, Carlos M. Silva, Americo R. Santos \\ Section of Urology, São Marcos Hospital, Braga, Portugal
}

\begin{abstract}
The term splenosis applies to the autotransplanted splenic tissue resulting from seeding in the context of past splenic trauma or surgery. We report a 42-year-old man with a history of splenectomy observed for an incidentally found retrovesical mass thought to be an ectopic testicle. The abdominal laparotomy revealed multiple focuses of pelvic splenosis. As splenosis can be diagnosed through specific imaging studies one should always consider it in differential diagnosis of a mass discovered years after splenic surgery or trauma.
\end{abstract}

Key words: spleen; wounds and injuries; splenosis; bladder

Int Braz. J Urol. 2006; 32: 678-80

\section{INTRODUCTION}

Ectopic splenic tissue is a cause of incidentally found mass leading to diagnostic confusion. It can present as a congenital accessory spleen typically localized medially to the orthotropic spleen or as a mass detected several years after a splenic surgery or trauma. These implants, resulting from seeding, can mimic a neoplasm. However, specific diagnostic tests can confirm diagnosis and avoid unnecessary surgery.

In this paper we discuss a case of an incidental retrovesical mass in a patient with an absent left testicle that lead us to think of an ectopic testicle.

\section{CASE REPORT}

A 42 year-old male patient with a history of Behçet disease and a motor vehicle accident 20 years before resulting in emergent splenectomy, was referred due to an incidental retrovesical mass. A routine abdominal ultrasound detected a solid retrovesical neoformation independent from seminal vesicles. The CT scan confirmed a $3.7 \times 2.5 \mathrm{~cm}$ mass (Figure-1).

No mass was identifiable on abdominal palpation or rectal exam. The left testicle was absent. IVU, transrectal ultrasound, and urethrocistoscopy were normal. The hypothesis of an ectopic left testicle tumor emerged. Testis tumor markers (DHL, ßHCG and $\alpha-\mathrm{FP}$ ) were within normal range.

A pelvic MRI was ordered and revealed a nodular structure with $3.7 \times 2.8 \mathrm{~cm}$, morphologically ovoid, paramedially and superiorly to seminal vesicles, medially to the sigmoid colon and independently from these structures. Its lobulated contour with intermediate signal on $\mathrm{T} 1$, similar to muscle, and hyper signal on $\mathrm{T} 2$, superior to muscle and inferior to fat, were against a testicle but uncertainty on the nature of the lesion remained. An open abdominal laparotomy was performed. Multiple bluish-red nodules scattered through the pelvis involving both visceral and parietal peritoneal surfaces, suggested ectopic splenic tissue (Figure-2). The histological exam confirmed splenosis. 


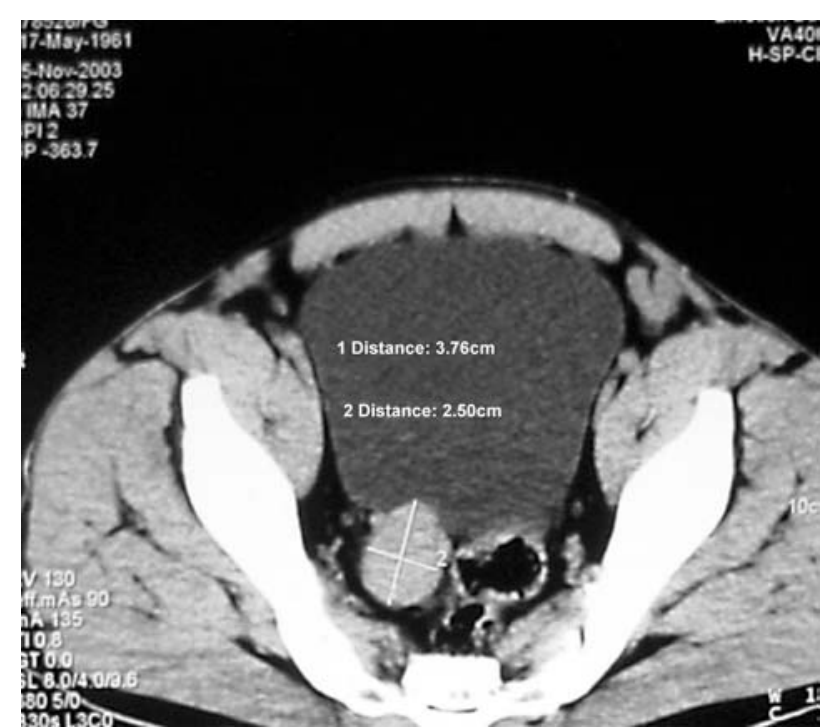

Figure 1-CT scan. A $3.7 \times 2.5$ cm hyperdense retrovesical mass.

\section{COMMENTS}

Splenosis affects one to two thirds of patients submitted to splenectomy for trauma (1). Implantation from seeding is most frequently in serosal surfaces of small and large intestine, greater omentum, parietal peritoneum, mesentery, diaphragm

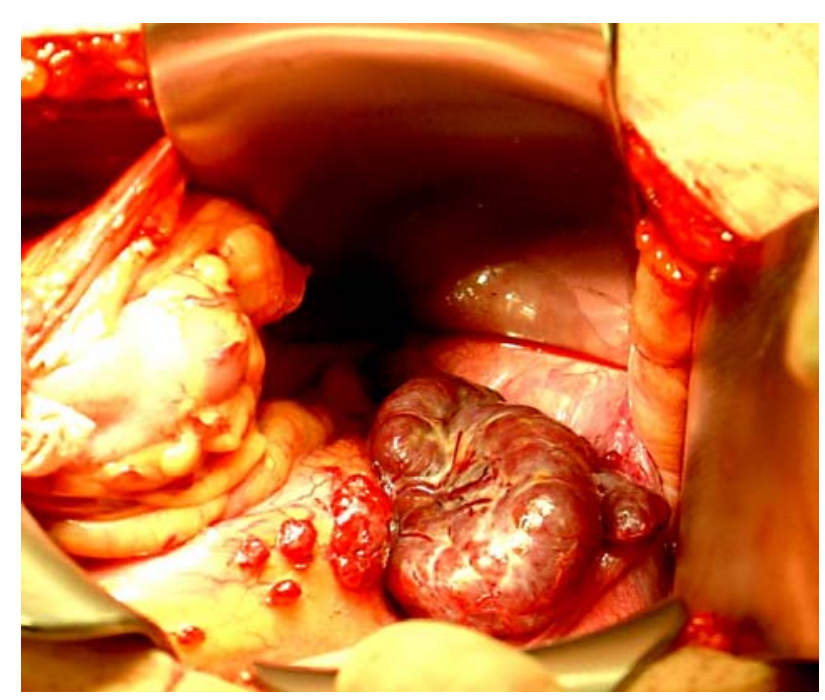

Figure 2 - Intraoperative picture revealing a large bluish-red mass and multiple small implants involving the peritoneum surface of pelvis suggesting ectopic splenic tissue. undersurface and more rarely, in cases of severe trauma, intrahepatic or even intrathoracic $(2,3)$.

Although splenosis can seldom present as a vague abdominal or testicular pain, intestinal obstruction from adhesions, GI bleeding and spontaneous rupture, it usually is an incidental finding during surgery, either laparoscopy or imaging (2).

When present as an incidental imaging mass it has been reported on to mimic renal, adrenal or abdominal tumors, metastases, lymphoma, endometriosis and ectopic testicles (1-4). Although usual imaging modalities (US, CT, MRI) are helpful to localize and determine the size, structure and relations with adjacent organs they are not specific.

If we had considered splenosis, signs of residual splenic tissue as the absence of Howell-Jolly bodies, siderocytes, Heinz bodies and pitted red cells on peripheral blood smear a could have been of help, but their presence is still possible due to less functioning splenosis tissue $(2,3)$

More specific and diagnostic studies using agents that are sequestered by reticulendothelial tissue, like ${ }^{99 \mathrm{~m}}$ technetium sufur colloid, ${ }^{99 \mathrm{~m}}$ technetium labeled heat-denatured autologous red blood cells or ${ }^{111}$ In-labeled platelets scans $(1,2)$ and recently ferumoxide-enhanced MRI (4) have been used.

In conclusion, all patients with a history of spleen surgery or trauma should consider the hypothesis of splenosis in differential diagnosis of a newly found mass.

\section{CONFLICT OF INTEREST}

None declared.

\section{REFERENCES}

1. Pumberger W, Wiesbauer P, Leitha T: Splenosis mimicking tumor recurrence in renal cell carcinoma: detection on selective spleen scintigraphy. J Pediatr Surg. 2001; 36: 1089-91.

2. Khosravi MR, Margulies DR, Alsabeh R, Nissen N, Phillips EH, Morgenstern L: Consider the diagnosis of splenosis for soft tissue masses long after any splenic injury. Am Surg. 2004; 70: 967-70. 
3. Weinstein RP, Genega EM, Dalbagni G: Splenosis mimicking transitional cell carcinoma. J Urol. 1999; 161: 1281.
4. Berman AJ, Zahalsky MP, Okon SA, Wagner JR: Distinguishing splenosis from renal masses using ferumoxide-enhanced magnetic resonance imaging. Urology. 2003; 62: 748.

Accepted after revision:

March 25, 2006

\author{
Correspondence address: \\ Dr. Jorge Cabral Ribeiro \\ Hospital de São Marcos, Section of Urology \\ Apartado 2242 \\ Braga, 4701-965, Portugal \\ Fax: + 35 125-3613334 \\ E-mail: jcabralribeiro@netcabo.pt
}

